\title{
INCLUSIVE PRIMARY EDUCATION IN BANGLADESH FOCUSING STUDENTS WITH DISABILITIES
}

\author{
Mohammad Zulfikar Ali \\ Institute of Education and Research (IER), University of Rajshahi, Bangladesh
}

\begin{abstract}
Inclusion is a globally recognized educational philosophy that ensures opportunities and participation of all students along with students with disabilities in all aspects of school life. The United Nations has recently set target (Goal 4) of the SDGs ensuring quality, equitable and inclusive education for all by the year 2030. Over the years Bangladesh has responded to the international declarations to ensure and promote inclusive education. It is developing model inclusive primary schools across the country. However, many children with disabilities in Bangladesh are still facing exclusion. Data of this phenomenological study were collected from forty school teachers from fifteen primary schools through FGD and questionnaire guided interviews. Ten classroom teaching were observed and the parents, students, the community people and concerned education officers were interviewed. The social constructivist theory and system theory constructed the theoretical framework of the study. The research found challenges of training, study materials and assistive devices, funds, rigid curriculum and weak coordination among community and schools. It recommended holistic approach and good collaboration among community and school to meet the challenges. The findings might regenerate in depth understanding on inclusive education for policy implementers and other researchers from the context of Bangladesh.
\end{abstract}

Keywords: Bangladesh, primary education, students with disabilities, inclusive education.

\section{Introduction}

This study is about the exploration of challenges of inclusive education focusing students with disabilities in primary schools of Bangladesh. As it is envisaged that 'inclusion and participation are essential to human dignity and to the enjoyment and exercise of human rights" (Salamanca Framework for Action, 1994). Inclusive education is the most common approach to address the educational needs of all children (Ainscow \& Miles, 2008). In respect of inclusion," all students attend and are welcomed by their neighborhood schools in ageappropriate, regular classes and are supported to learn, contribute and participate in all aspects of the life of the school."(Pamela R. Cook, 2014).

Education is considered as foundation of development, means of empowerment, and basis of equal and just society. With the acceptance of education as basic human right issue globally, many efforts has been made to improve in education system to increase access and to provide quality education for all. However, as exclusion is ingrained into the global social fabric in general and education in particular (Slee, 2013), still there are many children remained out of school and deprived from opportunity of education ( Regmi, 2017).

'Inclusion' in education is about ensuring the rights to education of all learners, regardless of their individual characteristics or difficulties, in order to build a more sustainable society(UNESCO 2003). However, inclusive education initiatives are often particularly focused on those groups who are traditionally excluded from educational opportunities of a country. Among these vulnerable groups, students with disabilities are often the most marginalized within education systems and within society in general. Traditionally, these students with 
disabilities experience exclusion, discrimination and segregation from the mainstream schooling and from their peers.

The inclusive education approach is particularly important for these students with disabilities. The world community advocate that education for the students with disabilities should be provided 'in integrated school settings" and "in the general school setting" (UN Convention 1993). "Inclusive education is the practice of teaching disabled students alongside their non-disabled peers in regular classroom settings, instead of segregating them in special classrooms" ( Giffen, 2011, quoted in Westwood , 2013 ). According to Idol (2006), inclusion means that students with special needs attend general school programs and are enrolled in ageappropriate classes for $100 \%$ of their schooling.

The global community under the umbrella of The United Nations ( UN, 2015) has recently set target (Goal 4) of the Sustainable Development Goals(SDG) ensuring quality, equitable and inclusive education for all by the year 2030. Inclusive education has now taken priority on the global agenda to ensure equal right to education for all (Ahsan T.M., 2013).

UNESCO (2009) defines inclusive education as:

"process aimed to offering quality education for all while respecting diversity and the different needs and abilities, characteristics and learning expectations of the students and communities, eliminating all forms of discrimination" (p.18).

Therefore, it might be anticipated that the values of inclusive education would ensure such welcoming environment in schools that would be free from the effects of negative forms of discrimination based on gender, culture, ethnicity, disability, religion or socio-economic and or geographic backgrounds ( UNESCO, 1994).

Despite the achievement of worldwide enormous progress in education,57 million school age children are still denied the opportunity to learn ( UNESCO, 2014). We come to know from the EFA Global Monitoring Report 2013/14 that girls make up about 54 percent of the global population of children out of school. The remaining half of the out-of-school population is split almost equally between children who enrolled but dropped out and those who are expected to enter school but will be older than the official primary school age, and so are more likely to eventually drop out ( UNESCO, 2014). It was also found in the report that children with disabilities still remained as most of the neglected and disadvantaged group in education. It was estimated that 93 million children under age 14 ( 5.1 percent of the world's children) were living with "moderate or severe" disability. Out of these, 13 million of the world's children experience severe disabilities ( UNESCO, 2014). Similarly, around half of the world's out of school population lives in conflict-affected countries. Furthermore, out of the 28.5 million primary school age children who were out of school in conflict-affected countries, 95 percent live in low and lower middle income countries (UNESCO, 2014).

According to a research report presented by Islam (Islam, M.M., 2016):

"Bangladesh is operating one of the largest primary education system in the world with about 20 million students. More than $80 \%$ of its total primary education provision is covered by the government. Here, Primary education starts from 6 years of age and continue up to grade V (5 years of education). By its constitution, Primary education is free \& compulsory for all primary school age children. Net enrolment rate in primary school is above $95 \%$. Gender parity is 1.06 . Cycle Dropout rate is $21 \%$ (significantly reduced in last few years). Contact hour is 3 hours for more than $80 \%$ schools . Teacher-Student Ratio is 1: 47. But still in Bangladesh we find that $2-9 \%$ children are not enrolling, among enrolled children all are not attending regularly, those who attends are not actively participating, all children are not promoting to next grade and not attaining grade wise competencies, $21 \%$ children are not completing primary cycle, $70 \%$ of primary graduates 
are not attaining all terminal competencies. Children with disability, children from ultra-poor families, urban slums, ethnic groups and hard to reach areas like island, coastal, hilly areas are mostly marginalized and excluded. Government of Bangladesh is giving its best effort to overcome these challenges through Sector Wide Program named Primary Education Development Program III (PEDP III). PLAN International Bangladesh in collaboration with Directorate of Primary Education (DPE) is trying to develop a Model of Inclusive Education in Bangladesh" ( Islam, M.M., 2016).

Over the years, like many other countries, the education system of Bangladesh has achieved remarkable changes. These tremendous changes are initiated to ensure brighter educational atmosphere in Bangladesh. Ensuring education for all learners in mainstream primary schools is one of those initiatives taken by the educational system and government of Bangladesh (Mehtab S., 2014).

Bangladesh made primary education compulsory for all children by enacting the Compulsory Primary Education Act 1990 ( Ministry of Primary and Mass Education, 1990). Bangladesh National Education Policy 2010 (MoE,2010) strongly recommends implementing inclusive education at primary education in the country. Bangladesh enacted a law known as the Protection of the Rights of the Persons with Disabilities Act, 2013 (The Ministry of Social Welfare, 2013). These policies and acts are stating the necessity of inclusive education for ensuring education for all children. A grate initiative of such policy change is the National Plan of Action Phase II ( NPA II) developed by the Ministry of Primary and Mass Education ( MoPME) implemented in the period 2003-2015 ( MoPME, 2003). NPA II Vision 5.2.iii of the Basic Primary Education by 2015 describes:

"All primary school-age children (6-10 years), boys and girls, including all ethnic groups, disadvantaged and disabled, are enrolled and successfully completing the primary cycle and achieving quality education ( MoPME, 2003: 28)".

The Directorate of Primary Education (DPE) under the Ministry of Primary and Mass Education ( MoPME) has already sent an office order/circular to all the primary schools in Bangladesh to include all children in their regular programs and provide required support to those children ( Directorate of Primary Education, 2007). Therefore, Bangladesh formally started implementing inclusive education since 2003 through a project titled the Second Primary Education Development Program known as PEDP-II by formally including different vulnerable children (it covers gender, children with disabilities, tribal children and socially disadvantaged children) into education ( Directorate of Primary Education, 2006 ).

However, still a lot of children are out of school or dropped out from school in Bangladesh and around 53\% of them are children with disabilities ( Ahsan, 2013). Teachers still feel less confident in including children with disabilities in their programs ( Forlin, Loreman, Sharma, \& Earle, 2009; Kim, 2011). The enrollment of children with disabilities in primary education is very low (less than $1 \%$ of total student population), taking into account the total number of children - 1,69,57,894 - enrolled in primary schools (Directorate of Primary Education [DPE], 2011). In addition, only $22 \%$ of children from the indigenous communities completed primary education during 2004 (Sarker \& Davey, 2009). There are more than 3 million children left out of school. They are from specific groups, including hard-to-reach children; children with disabilities; children in remote areas [Teagardens, Char, Haor-baor, disaster prone area etc.]; children living in slums; children living in extreme poverty; and working children (( Ahsan, 2013).

In this circumstances Bangladesh is implementing one of the biggest sector wide program titled third Primary Education Development Program ( PEDP III), where inclusive education is an important aspect (Ahsan, 2013). Article 17 of the Constitution outlines the goal of education as one offering a mass oriented, universal, free and compulsory education to all children in Bangladesh. In line with this goal, the focus of PEDP3 is to establish "an efficient, inclusive, and equitable primary education system delivering effective and relevant child-friendly 
learning to all Bangladesh's children from pre-primary through Grade 5 primary" (Annual Sector Performance Report - 2016 ).

The PEDP3 focuses on the expansion of decentralized planning, management and monitoring at district, Upazila and school levels. The preparation and implementation of the School Level Improvement Plans (SLIP) and Upazila Primary Education Plans (UPEP) play a role in reducing disparities and increasing participation within schools and Upazilas. Another dimension of decentralization is the delegation of administrative powers and functions of DPE in a more comprehensive and systematic manner, including the strengthening of field level offices through filling vacancies at PTIs, UEOs and URCs. This will involve capacity building programs to strengthen planning and monitoring functions of field level offices and providing personnel with leadership development (ASPR, 2016 ).

Even, considering the situation, the ministry of primary and mass education of Bangladesh started implementing 50 model inclusive primary schools spread across the country with collaboration of an NGO partner, the Plan International. The project was undertaken in five districts of Bangladesh (Hatibandha upazila of Lalmonirhat district, Jaldhaka upazila of Nilphamari district, Barguna Sadar upazila of Barguna district, Kulaura upazila of Mouluvibazar district and Dhaka Metropolitan City of Dhaka ).

Despite improved educational provision for children with disabilities and positive advance in policy on inclusive education, it is necessary to examine the reality or what is in practice at present in the context of Bangladesh through research. Moreover, Lindsay (2003) recognizes the needs of research in inclusive education to inform policy and practice. It is true that, without addressing the vital issues of access, participation, diversity and disability, the education system would not be inclusive (Regmi, 2017).

Present situation:

In line with the goal of the constitution of Bangladesh (Article 15 and 17) and its education policy (2010), the focus of the government of Bangladesh is to establish an efficient, inclusive, and equitable primary education system and it is delivering effective and relevant child-friendly learning to all children regardless of their special needs from pre-primary to Grade 5 primary education.

The number of CWDs among enrolled 18,59,360 children in pre-primary education in seven types of Primary Schools is total $=11,227$, boys $=6,322$, girls $=4,905$. (APSC, 2016 ).

Bangladesh made primary education compulsory for all children by enacting the Compulsory Primary Education Act 1990 ( Ministry of Primary and Mass Education, 1990).

Bangladesh primary education system is large -18.602 million students. The government primary schools and Newly Nationalized Primary Schools covered 13.389 million (72\%) students (APSC, 2016 ).

According to WFP Bangladesh Country Strategic Plan (2017-2020) :

'Bangladesh graduated to lower-middle-income country status in 2015 and enters the era of the Sustainable Development Goals (SDGs) from a solid base, having achieved significant progress towards the Millennium Development Goals for universal primary education, gender parity in basic education, and reduced child and maternal mortality' ( WFP, 2017) .

However, there remain many children with disabilities in Bangladesh who leave school before completing primary education and many children suffer from lower learning achievement as well as class repetition. 
Keeping these concerns in background, this phenomenological study aimed to explore the actual situation of inclusive primary education corresponded with the policy on inclusion in Bangladesh. With a holistic approach, the intent of this study was to investigate the area of inclusion in education from the perspectives of primary school teachers, parents of the students, the community and the government officials.

In this respect, the purpose of this research was to explore the perspectives and lived experiences of teachers, parents of the students, the community and other concerned government officials to address the challenges of implementation of inclusive education in inclusive government primary schools at the upazila ( a lower and sub-district level unit of public administration) levels of Bangladesh.

\section{Rationale of the study ( in brief):}

- Inclusive education, today, is being recommended as a means to provide education for all children, including the most marginalized group, the CWDs.

- In order to gain a greater understanding of inclusive practices for education of children with disabilities in primary schools, limited studies have been conducted.

- National Education Policy (2010) of Bangladesh ensures the inclusion of children with disabilities in mainstream schools and mentions when inclusion will not be possible, for severe physical and intellectual disabilities which limits even children's daily living skills, special education \& care will be provided (Ministry of Education, 2010).

- Bangladesh has made primary education compulsory for all children by enacting the Compulsory Primary Education Act 1990 ( Ministry of Primary and Mass Education, 1990).

- However, still a lot of children are out of school or dropped out from school in Bangladesh and around $53 \%$ of them are children with disabilities ( Ahsan, 2013).

- We have recognition and polices for inclusion. Now, it is time to find out how to implement inclusive education successfully.

Now, it is reasonable to examine and explore the perspectives and personal experiences of primary school teachers, the community, the students with and without disabilities and their respective parents to get insight into the day to day reality of including children with disabilities into mainstream education of Bangladesh.

The researcher wanted to gain personal insight into the lived experiences of participants and adopted phenomenological approach for the purpose of this study. The study attempted to assess the teaching strategies of implementation of inclusive education in primary schools classrooms.

Therefore, the intent of this study was to understand and explore the real scenario of inclusive education practices focusing children with disabilities in rural Upazila ( sub district ) level primary schools in Bangladesh.

\section{Research Methodology}

With a holistic approach, the intent of this study was to investigate the area of inclusion in education from the perspectives of primary school teachers, parents of the students, the community and the government officials. The researcher wanted to gain personal insight into the lived experiences of participants and adopted phenomenological approach for the purpose of this study. It used both the principles of constructivist theory and system theory to unveil the challenges towards inclusion of children with disabilities in mainstream primary schools in Bangladesh. 
Constructivism's main idea is that learners are capable of constructing their own knowledge. The knowledge constructed by learners can be from their personal experience or as a result of interaction with peers or with the teachers. That means a learner interaction is important because knowledge cannot be developed in isolation but through being in contact with others in the society or a given environment. Pelech and Pieper (2010: 8) believe that "constructivism is a philosophy that views knowledge as a subjective that is shaped and structured by one's experience". The researcher have chosen to work with Vygotsky's idea on social constructivism as the study intends to explore the field of inclusive education in Bangladesh with its social context and has a contribution on how its implementation is being done. Vygotsky's constructivist theory is better known as social constructivism. According to him, culture and social context are very important in cognitive development. To him, social context appear to be very important and human inquiry is embedded within culture which is embedded within social history (Pass, 2004).

The concept of system theory was introduced by Burtalanffy in 1937. He was a biologist and his theory was used to explain the interrelationship which exists between different organizations. Urie Bronfenbrenner (19172005), a Russian-born American psychologist, formulated the Ecological System theory to explain how the inherent qualities of a child and his environment interact to influence his development. According to him, " Ecological system theory is an approach to study of human development that consists of the scientific study of the progressive, mutual accommodation, throughout the life course, between an active, growing human being, and the changing properties of the immediate settings in which the developing person lives, as this process is affected by the relations between these settings, and by the large contexts in which the settings are embedded" (Bronfenbrenner, U., 1989). Different writers have used the different terms and ideas related to system theory. For example, in educational context, Griffiths (1964), Senge (1990) and Morgan (1997) have incorporated the system concepts into theoretical constructs and their application to the leadership (Irby, 2013). In any system there are things which are interrelated with one another that make the whole system more than just the sum of its element.

In addition to constructivism theory the researcher decided to use system theory because schools as organizations do not function alone, it function as a system which includes many stakeholders. These stakeholders are like the ministry of education, head teachers, community, parents and teachers. In the implementation of inclusive education in primary schools all these stakeholders are included. Therefore, system theory would help to explain more on how school should function as a system towards the implementation of inclusive education in primary schools of Bangladesh.

The basic assumption of this design is to use both quantitative and qualitative methods in combination to provide a better understanding of the research problem and question than either method by itself (Creswell, 2014).With reference to social science research, less structured design is preferred because it helps to make research process more open and transparent. As this study was intended to explore the problems associated with the practice of inclusive education in Bangladesh context, the study has implied mixed methods research design.

The major rational for selecting mixed method research design was to use both qualitative and quantitative data to assess the theoretical and practical situation of inclusive education in Bangladesh. The practice of values and principles is crucial and complex because the process of implementation involves different people from different contexts and persuasions. The actual situation of practice depends on the interpretation of policy, expectations of different actors, current debates, tensions and negotiations. In order to understand such factors, this study has used mixed methods design to gain in depth understanding of the participant regarding the issues and problems that affects to the practice of inclusive education at school level. 
In this research, qualitative research design was employed for better understanding of inclusive education practices. The phenomenological approach was performed in this study to get an in-depth and lived experiences of the inclusive education practices with a focus on the CWDs in the schools level of a upazilla in Bangladesh.

The convergence parallel design was used as research method. Data were collected purposively by the researcher employing multiple tools namely documents study, questionnaire, observation, case study, focus group discussions and individual interviews.

The research was conducted between March and August 2017 in 15 schools, including ten model inclusive primary schools and five other regular schools in Jaldhaka Upazila of Nilphamari District of Bangladesh. In total, the research involved 100 participants including children with disabilities, their peers without disabilities at school, parents, SMC leaders, community, teachers, head teachers and education officers.

Forty primary school teachers were participated and ten classroom teaching were observed and twenty parents, twenty five students, ten community people, three school managing committee leaders and two concerned education officers were interviewed in order to obtain desired information.

In this research, qualitative research design was employed for better understanding of inclusive education practices. The phenomenological approach was performed in this study to get an in-depth understanding and lived experiences of the inclusive education practices with a focus on the children with disabilities in the schools level of a upazilla in Bangladesh.

\section{Research Findings and Discussion}

This research was guided by three research objectives:

- The first objective was to explore the primary school teacher's views ( understanding, challenges and suggestions ) on inclusive education.

- The second objective was to assess the kind of teaching strategies that teachers use in their inclusive classrooms.

- The third objective was to explore the students and their guardian's views towards inclusion of students with disabilities into the regular classrooms .

Limitation: Due to the demarcated short extent, only the first objective is presented and discussed in this article.

Findings were collected by using multiple tools of research method, which observation, case study, focus group discussion and phenomenological interviews. It was important to use observation method for these questions in order to have plenty of information on the challenges of implementing inclusive education in primary schools of Bangladesh. Data collected from interview and observation were analyzed by the use of questions and two theories viz. the System Theory and the theory of Constructivism. Descriptive type of data analysis was done.

\section{Teacher's views on inclusive education:}

Understanding on inclusive education:

It was the first specific objective of the study. The teachers were interviewed to judge their concept of inclusive education, the need for inclusive education practice and its implementation challenges as they had gained classroom experiences. 
In responding to the question on the concept of inclusive education teachers of inclusive model primary schools expressed all most the same views according to their understanding. But the other non model regular primary school teachers showed very poor conception on inclusive education. These schools are in principle inclusive but needs more development in practice.

All teachers of ten model inclusive primary schools shared the same view of what the term inclusion mean, or certainly what it ought to mean for children with disabilities and special educational needs attending mainstream school.

"Inclusion means being actively involved and participating in whatever the other children are participating in... That's what inclusion is all about, it's not just being here for Bangla, it's about being part of this class, and socially doing the things that they were doing" (Teacher E1 ).

Teacher E believed that children should be actively involved in all aspects of school life - be it in the classroom, a school play, having lunch with friends - to generally be part of everything the other children are doing, at a level that can be adapted to the child's ability. This corresponds with the definition of inclusion proposed by Cumming and Wong (2010), which suggests that children with disabilities have a right to access, participate and be equally included in education alongside their peers.

"It ensures that type of education which includes different types of children from different casts, religion, economic status, physical and mental conditions and sexual orientations, all are learning the same lesson in the same classes with the instruction of the same teacher. If there's anything going on, all students are involved in it in some shape or form " ( Teacher B1).

Teacher B from his explanations had revealed reasonable knowledge on inclusive education. From this explanation it showed that the respondent was aware on inclusive education since he was able to give a general concept on the question he was asked.

The following figures show the distinctive understanding of teachers of model inclusive primary schools and ordinary regular primary schools on inclusive education:

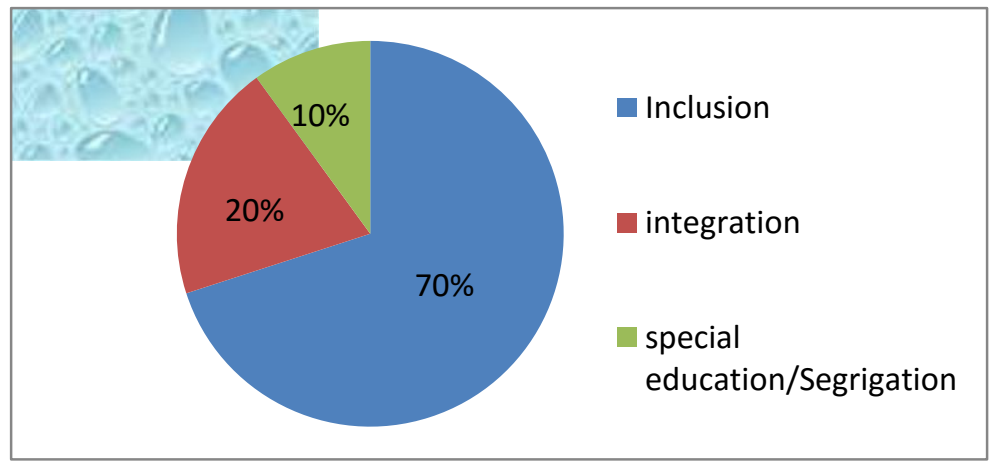

Figure 1: Model primary school teacher's understanding on inclusive education

Figure: 1 shows that most of the teachers of ten model inclusive primary schools shared all most the same view of what the term inclusion mean and they were relevant to the notion on inclusive education. 


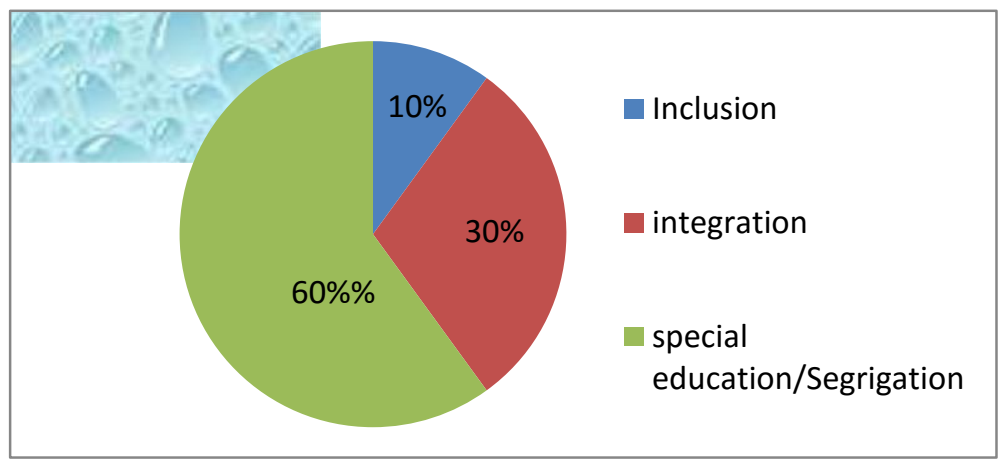

Figure 2: Regular primary school teacher's understanding on inclusive education

On the contrary, Figure: 2 shows that the teachers of other five primary schools except the model inclusive primary schools possess very limited idea on inclusive education and even they were mixing it either with the idea of integration or of special education.

Need for inclusive education:

Teachers expressed the potential benefits of inclusive education practice. Most of the teachers possessed that the students with disabilities had the same rights to education like others in the same school.

Teacher F2 said :"Students with disabilities become psychologically strong if they get chance to be educated with their non disabled peers. .. I was afraid when I found one visually impaired student in my class. But within a short time, I noticed that all the other students were helping her". Then she concluded that inclusive education was supporting to collaboration among students with and without disabilities.

Teacher G1 responded, "... I think that inclusive education is beneficial for all students because it is ensuring better acceptance of students with disabilities, creating chances for them to receive education in their familiar environment".

Teacher N2 disagreed with other teachers and said: " We've nothing to say, it's a government order. But it is not possible to include severely disabled, specially the children with intellectual disabilities. They need special care with special teachers. It's not possible with three days training. However we are discovering new methods of teaching every day to teach different types of children in the same inclusive school."

Teacher Z1 of a model inclusive primary school explained: "Our school is different from other schools because our school provides structural support for students with disabilities and we practice cooperative teaching and learning. These are much more helpful for students with disabilities. It is also helpful to manage a big class size and to monitor the children with special needs". 

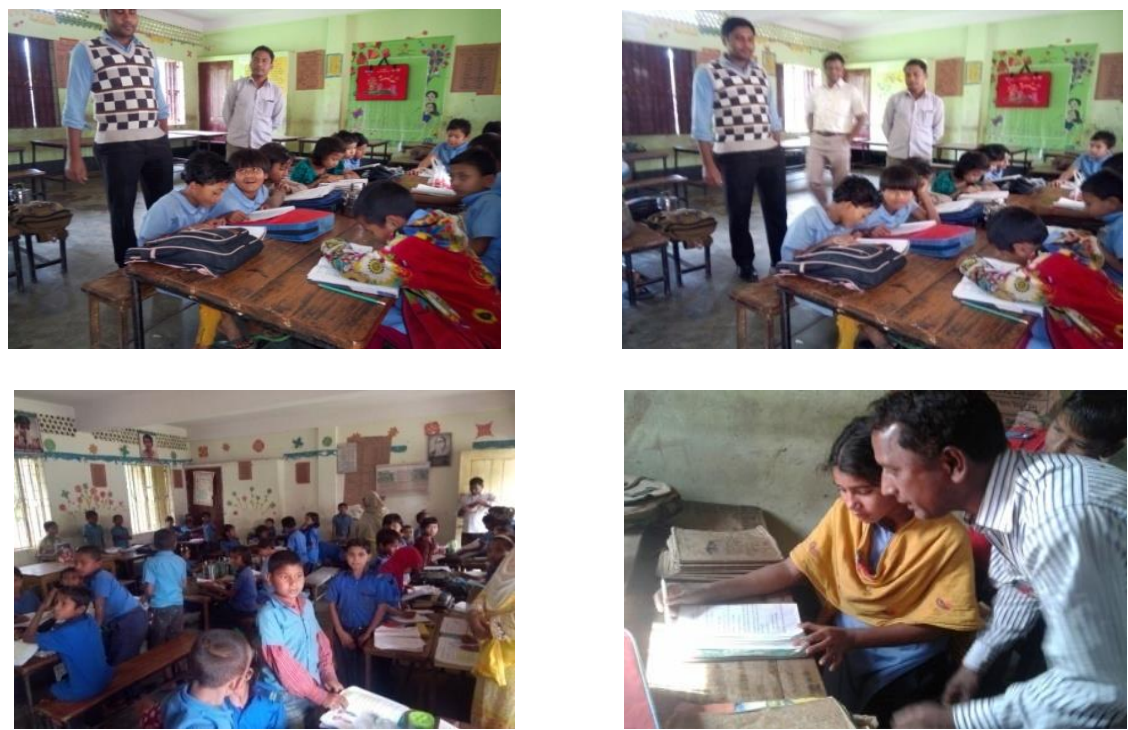

Image 1: Cooperative teaching practiced in inclusive model primary schools.

\section{Challenges towards implementation of inclusive education}

In response to the question, "What are the barriers and challenges to inclusive education practice in your school?"- the teachers identified multidimensional barriers and significant challenges.

Accessibility in terms of physical admittance was identified as a problem in some ordinary regular primary schools for students with physical disabilities. "There is no ramp in my school and the classrooms are not sufficient enough. It is very difficult for the physically disabled wheelchair users to go upstairs to attend classes".( Teacher J2)

All the teachers indicated that their large class sizes were barriers to effective teaching and learning. One respondent said, " How could I manage a class where usually 70 students are present. Seating arrangements are not comfortable for them". ( Teacher S1).

Many participants also identified centralized policy-making as a barrier. A teacher commented: " I am bound to run according to the guidelines of the text book. I have nothing to do in decision making for ensuring success of my students. I can't revise the rigid curriculum for the children with disabilities. The assessment system is also very rigid without any consideration for students with disabilities." (Teacher P1).

The findings explored that most of the respondents were in favor of inclusive education practices, but faced enormous challenges to achieve this goal. The findings also revealed that most of the teachers did not have academic background and proper training in inclusive education. On an average, each model inclusive primary school had only two teachers trained on brail books and sign languages to conduct an inclusive classroom for children with disabilities. That meant from the findings that it was evident that lack of trained and experienced teachers owned teaching in inclusive education reduced the skill to meet specific needs of the learners. This was also evident in literature review as Winger (2008: 18) who noted that "low quality of teacher education or lack of qualified teachers might be one reason behind the poor learning outcome".

The major challenges identified by the teachers towards implementation of inclusive education in their schools might be summarized as follows:

1. Lack of training;

2. Insufficient study materials and assistive devices

3. Inadequate funds 
4. Rigid curriculum and

5. Weak coordination (among different government offices, community and schools).

To overcome the challenges towards implementation of inclusive education in rural Upazila (sub-district) level primary schools focusing students with disabilities in Bangladesh the researcher suggested the following recommendations.

\section{Recommendations for implementation of inclusive education}

- $\quad$ Proper training on inclusive education for teachers

- Awareness programs for parents and community leaders

- Allocation of sufficient government fund to support IE and proper monitoring

- Revision of curriculum to make it flexible and

- Teacher empowerment to use different ways of teaching students with different educational needs in their classes

- Proper coordination among teachers, parents, SMC members, community people, head teachers, education officers, department of health, department of social welfare, department of education, department of public administration and different NGOs.

\section{Conclusion}

The study reflected the practice of inclusive education in rural primary schools in Bangladesh focusing students with disabilities.

Most of the teachers predicted that the aim of inclusive education will be successful if they are supported with appropriate school infrastructure, teaching materials, assistive devices for children with disabilities and good cooperation of the community and strong support of administration. It validated that children with moderate disabilities could be educated successfully in an inclusive environment of a local primary school.

The study proposed initiatives to be taken to overcome the mentioned challenges and suggested more collaborative efforts to build up the culture of inclusion in schools and promote an effective practice of inclusive education for all children including children with disabilities in Bangladesh.

\section{Acknowledgements}

I would like to acknowledge and thank Professor Dr. Katherine Lee from Hawaii of USA, Professor Dr. S.M. Wahiduzzaman, the Director General, Directorate of Secondary and Higher Education, Bangladesh, learned professors of IER of Rajshahi University and Professor Dr. Mustafa Kamal Akand, my research supervisor for their kind and cordial support. I am indebted to the University Grants Commission of Bangladesh for awarding me with the scholarship to support financially. I am also thankful to all the teachers, parents, students, community people and education officers of Jaldhaka upazila of Nilphamari district in Bangladesh who took part in this study 


\section{References}

Ahsan, M. T.( 2013) National baseline study for developing a model of inclusive education in Bangladesh project based on secondary data, Dhaka: Quality Primary Education Programme PLAN Bangladesh.

Ainscow, M. \& Miles, S. ( 2008). Making education for all inclusive: where next? Prospects, 38, 15-34.

DPE (2011). Third primary education development program ( PEDP3): Main document. Dhaka: DPE.

Idol, L. (2006). Toward inclusion of special education in general education. Remedial \& Special Education, 27, 77-94.

Irby, J. B., Brown, G., Alecio, R. F. \& Jackson, S. (2013). The handbook of Educational Theories. Charlote, North Carolina

Islam, M.M., Developing a Model of Inclusive Education in Bangladesh, Zero Project Conference 2016 Vienna, Austria, February 11, 2016.

Kim, J ( 2011). Influence of teacher preparation programs on pre service teachers' attitudes towards inclusion. International Journal of Inclusive Education, 15(3), 355 -377.

Ministry of Education (2010), The national education policy 2010 . Dhaka: Government of Bangladesh

Mitchell, D. (2014). What really works in special and inclusive education: Using evidence-based teaching strategies. Second edition. Abingdon Oxon: Routledge

Regmi, N.P.(2017). Inclusive Education in Nepal from Theory to Practice, Ludwig-Maximilians-University.

UN(2015). Sustainable development goals: 17 goals to transform our world. UN. Retrieved from : http://www.un.org/sustainabledevelopment

UNESCO. (1994), The Salamanca statement and framework for action on special needs education. Salamanca, Spain

UNESCO (2009). Inclusive education: The way of the future. Final Report of the International Conference of Education (48th Session). Paris: UNESCO.

Westwood, P.(2013). Inclusive and adaptive Teaching: Meeting the challenges of diversity in the classroom. London: Routledge. 